\title{
Stress and Fatigue of Connecting Rod in Light Vehicle Engine
}

\author{
Bin Zheng, Yongqi Liu ${ }^{*}$ and Ruixiang Liu
}

\author{
School of Transportation and Vehicle Engineering, Shandong University of Technology, Zibo 255049, China
}

\begin{abstract}
The connecting rod (CR) is the main moving parts and an important component of engine. If the reliability is not strong enough, fatigue failure of the CR would occur, thereby leading to component fracture and engine failure. So much so that CR fracture. It will lead to engine fault as well as serious outcome. In this paper, stress distribution and fatigue life of CR in light vehicle engine were analyzed using the commercial 3D finite element software, ANSYS ${ }^{\mathrm{TM}}$. The results showed that the medial surface of small end will be the critical surface whereby damage will initiate at the maximum stretch condition. The maximum stress and deformation values are $190.23 \mathrm{MPa}$ and $0.0507 \mathrm{~mm}$ respectively. The critical location is at the transition region between the big end and connecting shank at maximum compression condition. The maximum stress and deformation values are $459.21 \mathrm{MPa}$ and $0.0702283 \mathrm{~mm}$ respectively. Safety factor is 1.584. In order to increase the reliability of CR, some improvement is carried out. Safety factor of CR increases by $59 \%$.
\end{abstract}

Keywords: CR, finite element analysis, light vehicle engine, stress distribution, fatigue life, safety factor.

\section{INTRODUCTION}

One source of energy in automobile industry is internal combustion engine. IC engine converts chemical energy into mechanical energy in the form of reciprocating motion of piston. Crankshaft and CR convert reciprocating motion into rotary motion. $\mathrm{CR}$ is one of the important driving parts of light vehicle engine. The CR experiences various forces of piston acceleration and deceleration from the stroking motion, loads generated by friction and the load by the cylinder pressure during the combustion stroke. Under normal operating condition, the design of the CR for infinite number of cycles is based on these forces such that designed $\mathrm{CR}$ does not exceed the desired strength during the life span [1-3]. If it is not strong enough, fatigue failure of the CR would occur, thereby leading to component fracture and engine failure. So much so that CR fracture. It will lead to engine fault as well as serious outcome. As an effective analysis method, finite element analysis has been used widely in the design of CR [4-15].

With the rapid development of transportation trade, light vehicle is employed more and more widely. In this paper, stress distribution and fatigue life of $C R$ in light vehicle engine were analyzed using the commercial 3D finite element software, ANSYS ${ }^{\mathrm{TM}}$.

\section{MODEL BUILDING}

The material of $\mathrm{CR}$ is $40 \mathrm{Cr}$ steel. Main performance parameters are shown in Table $\mathbf{1}$.

Building an accurate and reliable calculating model is one of the key steps of analysis with finite element analysis. During the model development, the geometry of the finite

*Address correspondence to this author at the School of Transportation and Vehicle Engineering, Shandong University of Technology, Zibo 255049, China; Tel: +86-533-2782616; Fax: +86-533-2786837;

E-mail: liuyq65@163.com element model should be built according to the real one as close as possible. However, if the structure of the object is complex, it can be very difficult, even impossible to build the model in accordance with the real one. Therefore, approximate simplification is necessary. In this paper, the big end of CR is simplified. Bearing shell, bushing and bolts of $\mathrm{CR}$ are ignored. Big end cover and body of CR are taken as a whole model. In order to avoid a large difference in the finite element mesh sizes which would reduce element quality and calculation accurarcy, geometrical simplification is done to the little beveling and circular beads that hardly affected the strength of the CR.

In order to ensure calculation accuracy, 20-node tetrahedron element SOLID 187 is employed. The model is meshed using the method of free meshing. Stress concentrated parts such as the transition location of small end and CR shank, the transition location of big end and inner sides of I-shaped cross-section of CR shank, are checked. The final CR model has 23793 nodes and 50093 elements. The mesh of the CR is shown in Fig. (1). The Stress distribution, deformation and safety factor are shown.

Table 1. Main Performance Parameter

\begin{tabular}{|c|c|c|c|}
\hline $\begin{array}{c}\text { Young's Modulus } \\
\text { [MPa] }\end{array}$ & $\begin{array}{c}\text { Poisson's } \\
\text { Ration }\end{array}$ & $\begin{array}{c}\text { Breaking Point } \\
{[\text { MPa] }}\end{array}$ & $\begin{array}{c}\text { Yield Limit } \\
{[\text { MPa] }}\end{array}$ \\
\hline \hline $2.1 \mathrm{e} 5$ & 0.3 & 980 & 785 \\
\hline
\end{tabular}

\section{APPLIED LOADS}

The CR model has periodic external loads which consists of two parts. One is gas combustion pressure transformed by piston crown, which compresses CR. The other is inertia force caused by high-speed moving of piston-CR, which stretches CR. Therefore, during the process of analysis, the main load is maximum combustion pressure, inertia force of piston unit and inertia force of CR unit. 


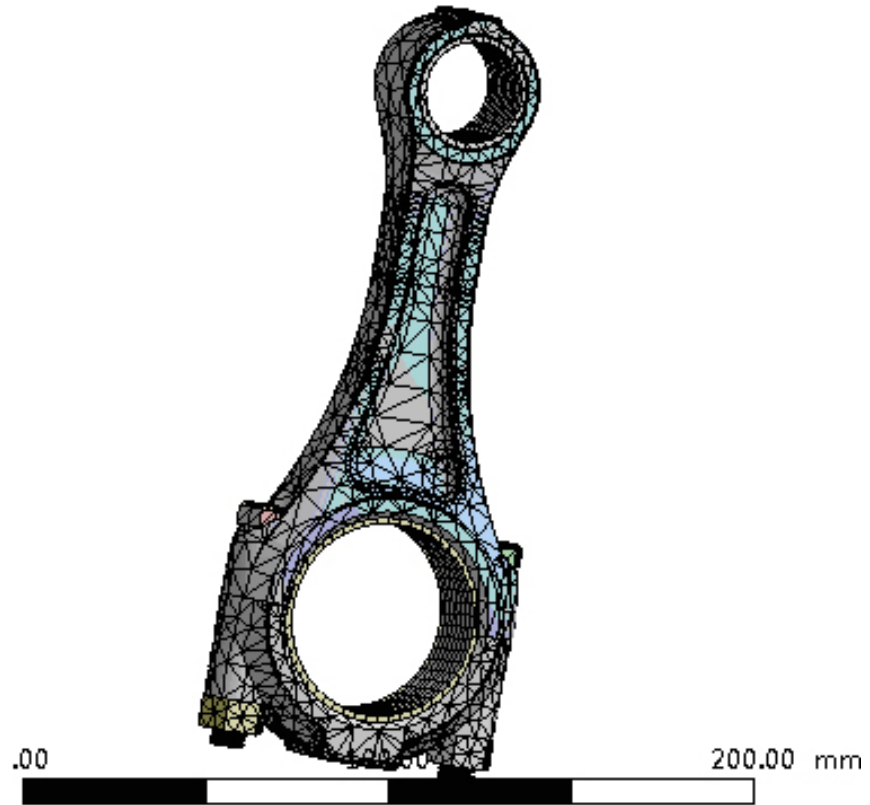

Fig. (1). Mesh of CR.

\subsection{Combustion Pressure}

Combustion pressure is the gas pressure caused by gas combustion. It presses on the piston and transmits the force to the small end of the CR via the piston pin. Gas combustion pressure can be worked out by equation (1).

$$
F=P_{g} \frac{\pi D^{2}}{4}
$$

where $P_{g}$ is manometer pressure of cylinder and $D$ is diameter of cylinder.

\subsection{Inertia Force of Piston Unit}

Piston unit consists of piston, piston ring, piston pin and piston pin circlip. The mass of piston unit is mass summation of all the parts. Inertia force of the piston unit works on the piston pin and transmits the force to the CR. The inertia force can be worked out by equation (2).

$$
F_{1}=m_{p} R \omega^{2}(1+\lambda)
$$

where $m_{p}$ is mass of piston unit, $R$ is radius of crank, $\omega$ is angular velocity of crank and $\lambda$ is crank link ratio.

\subsection{Inertia Force of CR Unit}

CR unit consists of CR shank, big end cover, bearing shell, bolt and bush. The mass of CR unit is made up of these parts. In order to simplify calculation, the mass of the CR which induces complicated movement is divided into two parts. One part concentrates on small end of CR, which is considered to make movement with piston. The other part concentrates on big end of $\mathrm{CR}$, which is considered to make rotary motion with crank. So inertia force of CR consists of reciprocal inertia force on small end and rotary inertia force on big end.

The reciprocal inertia force of small end is calculated by equation (3).

$F_{2}=m_{1} R \omega^{2}(1+\lambda)$
The rotary inertia force of big end is calculated by equation (4).

$$
F_{3}=m_{2} R(\omega \lambda)^{2}
$$

where $m_{l}$ is mass of small end of CR, $m_{2}$ is mass of big end of $\mathrm{CR}, R$ is radius of crank, $\omega$ is angular velocity of crank and $\lambda$ is crank link ratio.

The analysis of CR consists of two conditions, the maximum stretch condition and the maximum compression condition. The load is applied to inner surfaces of big end and small end. The load distribution is second-degree parabola in axial direction and cosine in radial direction.

Safety factor is calculated by equation (5):

$$
n=\frac{\sigma_{-1 Z}}{\frac{\sigma_{a}}{\varepsilon_{\sigma}^{\prime \prime}}+\varphi_{\sigma} \sigma_{m}}
$$

where $\sigma_{-l Z}$ is yield stress, $\sigma_{a}$ is stress amplitude, $\varepsilon_{\sigma}$ " is surface roughness, $\varphi_{\sigma}$ is fatigue life factor and $\sigma_{m}$ is mean stress.

\section{RESULTS AND DISCUSSION}

The stress distribution and deformation of $\mathrm{CR}$ at the maximum stretch condition are shown in Figs. $(\mathbf{2}, \mathbf{3})$. The results show that the medial surface of small end will be the critical surface whereby damage will initiate at the maximum stretch condition. The stresses are high at the CR shank, but stress distribution is relatively uniform. The maximum stress and deformation values are $190.23 \mathrm{MPa}$ and $0.0507 \mathrm{~mm}$ respectively.

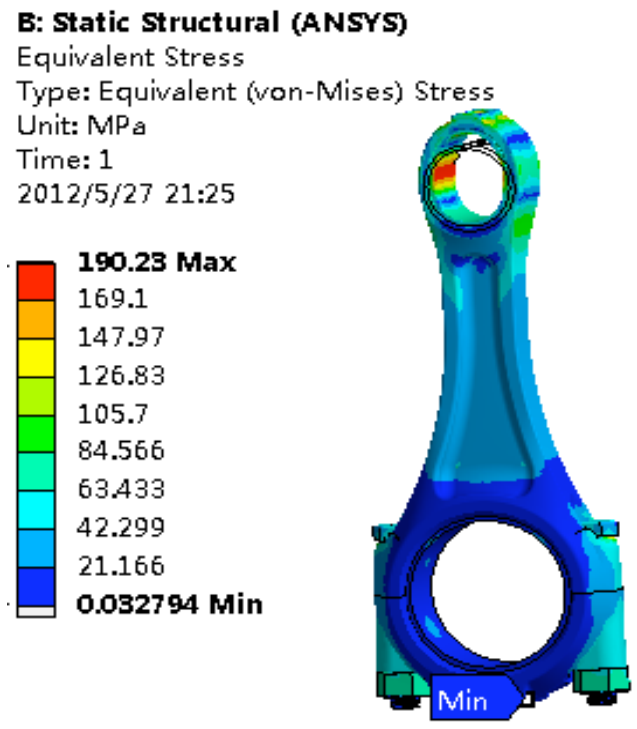

Fig. (2). Stress distribution of CR at maximum stretch condition.

Stress distribution and deformation of $\mathrm{CR}$ at maximum compression condition are shown in Figs. $(\mathbf{4}, \mathbf{5})$. The results show that the critical location is at the transition region between the big end and connecting shank at maximum compression condition. The maximum stress and deformation values are $459.21 \mathrm{MPa}$ and $0.0702283 \mathrm{~mm}$ respectively.

Safety factor of CR is shown in Fig. (6). The results show that safety factor of CR is 1.584 . Fatigue resistance of $\mathrm{CR}$ is good. 
Time: 1

2012/5/27 21:27
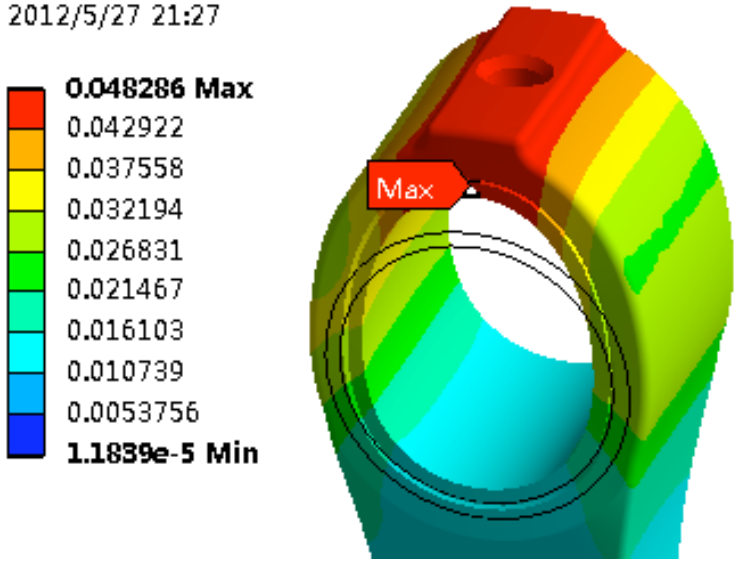

Fig. (3). Deformation of CR at maximum stretch condition.

B: Static Structura
Equivalent Stress
Type: Equivalent (von
Unit: MPa
Time: 1
2012/5/27 21:14
\begin{tabular}{|l}
$\mathbf{4 5 9 . 2 1}$ Max \\
408.19 \\
357.18 \\
306.16 \\
255.14 \\
204.12 \\
153.11 \\
102.09 \\
51.072 \\
$0.054374 ~ M i n$
\end{tabular}

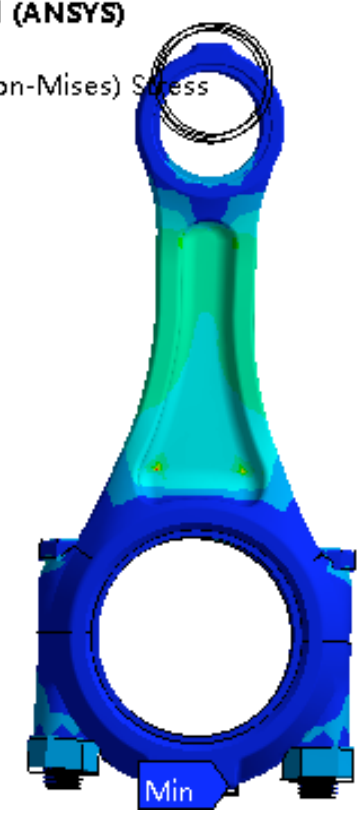

Fig. (4). Stress distribution of $\mathrm{CR}$ at maximum compression condition.

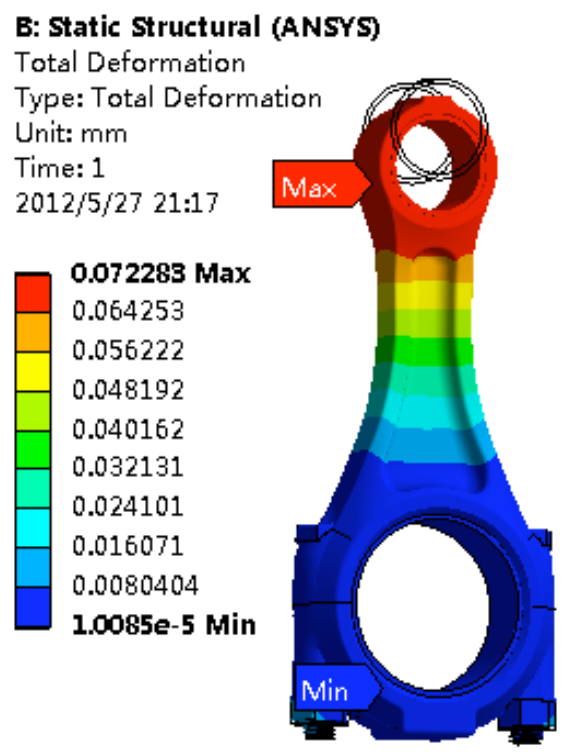

Fig. (5). Deformation of CR at maximum compression condition.

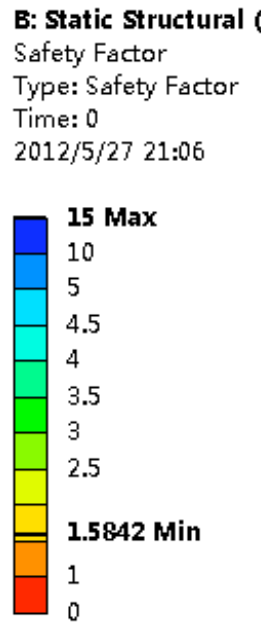

B: Static Structural (ANSYS)

Safety Factor

Time: 0

$2012 / 5 / 2721: 06$

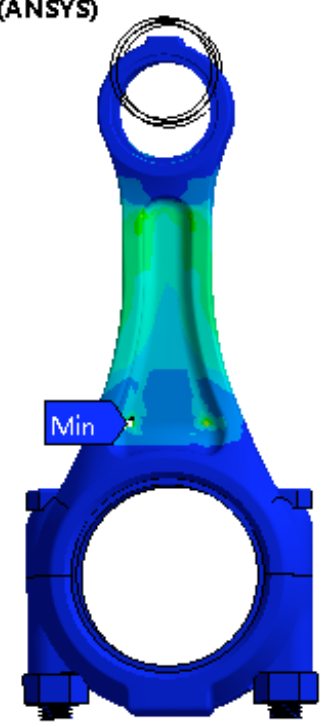

Fig. (6). Fatigue safety factor of CR.

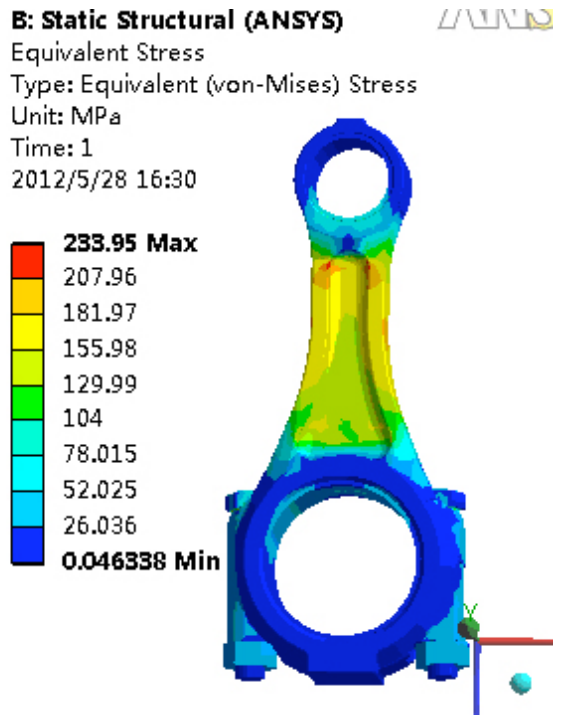

Fig. (7). Stress distribution of $\mathrm{CR}$ at maximum compression condition after improvement.

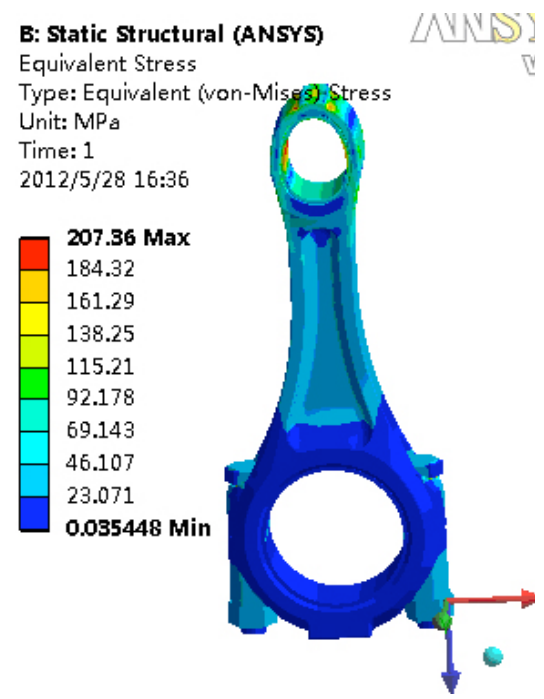

Fig. (8). Stress distribution of $\mathrm{CR}$ at maximum stretch condition after improvement. 


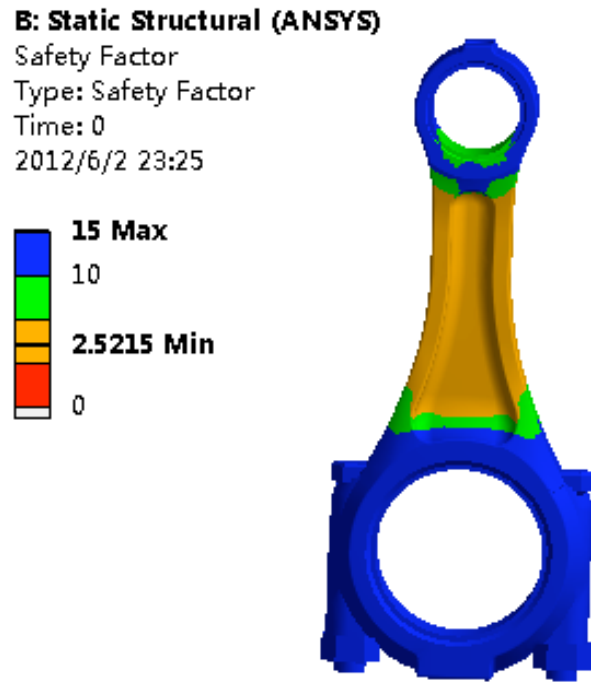

Fig. (9). Fatigue safety factor of CR after improvement.

\section{IMPROVEMENT OF CR STRUCTURE}

Safety factor of the whole CR is 1.584 , which is only a little greater than design safety factor. In order to increase the reliability of CR, some improvement is carried out. According to the analysis results, the main stress concentration locations are the transition region between big end and CR shank and the I-shaped cross-section at big end. So it is necessary to improve the structure of the two positions. Improvement is mainly done at three structural parameters: 1. knuckle of big end and CR shank; 2 . chamfering of I-shaped cross-section at big end; 3. edge chamfering of I-shaped cross-section at big end. the calculation results after improvement are shown in Figs. (79). Maximum stress value decreases $49 \%$ at maximum compression condition. Maximum stress value increases $8.95 \%$ at maximum stretch condition. Safety factor of CR increases by $59 \%$.

\section{CONCLUSIONS}

The medial surface of small end will be the critical surface whereby damage will initiate at the maximum stretch condition. The stresses are high at the CR shank, but stress distribution is relatively uniform. The maximum stress and deformation values are $190.23 \mathrm{MPa}$ and $0.0507 \mathrm{~mm}$ respectively. The critical location is at the transition region between the big end and connecting shank at maximum compression condition. The maximum stress and deformation values are $459.21 \mathrm{MPa}$ and $0.0702283 \mathrm{~mm}$ respectively. Safety factor is 1.584 . In order to increase the reliability of CR, some improvement is carried out. Maximum stress value decreases $49 \%$ at maximum compression condition. Maximum stress value increases
$8.95 \%$ at maximum stretch condition. Safety factor of CR increases by $59 \%$.

\section{CONFLICT OF INTEREST}

The authors confirm that this article content has no conflict of interest.

\section{ACKNOWLEDGEMENTS}

This work was financially supported by the National High Technology Research and Development Program ("863"Program) of China (No.2009AA063202), Shandong Natural Science Foundation (No. ZR2010EM070).

\section{REFERENCES}

[1] S. Khare, O.P. Singh, K. Bapanna Dora, and C. Sasun, "Spalling investigation of connecting rod", Eng. Failure Analysis, vol. 19, pp. 77-86, January 2012.

[2] B. Kim, and K. Kim, "Thermo-elastohydrodynamic analysis of connecting rod bearing in internal combustion engine", J Tribol, vol. 123, pp. 7-18, March 2001.

[3] R. Roger, "Fatigue failure of a connecting rod", Engineering Failure Analysis, vol. 3, pp. 13-28, January 1996.

[4] S. Griza, F. Bertoni, G. Zanon, A. Reguly, T.R. Strohaecker, "Fatigue in engine connecting rod CR bolt due to forming laps", Engineering Failure Analysis, vol. 16, pp. 1542-1548, July 2009.

[5] M. K. Lee, H. Lee, T. S. Lee, and H. Jang, "Buckling sensitivity of a connecting rod to the shank sectional area reduction", Materials \& Design, vol. 31, pp. 2796-2803, June 2010.

[6] S. Griza, F. Bertoni, G. Zanon, A. Reguly, and T.R. Strohaecker, "Fatigue in engine connecting rod bolt due to forming laps", Engineering Failure Analysis, vol. 16, pp. 1542-1548, July 2009.

[7] H. S. Kima, T. G. Kimb, T. J. Chung, H. S. Kim, and Soon-Jik Hong, "Fatigue characteristics of high strength C70S6 and SMA40 steels", Materials Science and Engineering: A, vol. 527, pp. 28132818, May 2010

[8] F. Yin, G.X. Wang, S.Z. Hong, and Z.P. Zeng, "Technological study of liquid die forging for the aluminum alloy connecting rod of an air compressor", Journal of Materials Processing Technology, vol. 139, pp. 462-464, August 2003.

[9] J.C. Zhang, X.H. Li, and G. Sun, "CR design based on finite element analysis”, Tractor \& Farm Transporter, vol. 33, pp. 27-30, January 2006.

[10] Z.J. Tang, Z.X. Zuo, and R.H. Zhang, "Development of finite element analysis for CR of internal combustion engines", China Mechanical Engineering, vol. 15, pp. 365-369, April 2004.

[11] W.F. Dai, W.X. Fan, and Z.J. Cheng, "The 3D finite element analysis of diesel engine connecting rod based on ANSYS", Small Internal Combustion Engine and Motorcycle, vol. 37, pp. 48-50, January 2008.

[12] K. HO-LE, "Finite Element Mesh Generation Methids", Computer Aided Design, vol. 20, pp. 27-38, January 1998.

[13] S.T. Xiong. "Analysis of CR structure of TC490ZQ vehicular diesel engine", Small Internal Combustion Engine and Motorcycle, vol. 30, pp. 22-23, October 2001.

[14] D.H. Tu, S.L. Jiang, and M.L. Cao, "The FE analysis for 498 CR assembly", Transactions of CSICE, vol. 22, pp. 176-177, February 2004.

[15] H. Wu, F. Wang, and H.Y. Gan, "The three-dimensional fine analysis for the CR of high-power diesel engines", Chinese Internal Combustion Engine Engineering, vol. 24, pp. 31-32, December 2003. 